\title{
Continuous-Wave Doppler Ultrasound Mode
}

National Cancer Institute

\section{Source}

National Cancer Institute. Continuous-Wave Doppler Ultrasound Mode. NCI Thesaurus.

Code C130062.

A method of ultrasound imaging that uses Doppler signals that are continuously sent and received along a single line to measure both direction and velocity of blood flow. 